\title{
KAJIAN ANALISIS LAPIS PERKERASAN JALAN (AC-BC) TELUK DAWAN - TELUK BUAN KEC. DENDANG KAB. TANJUNG JABUNG TIMUR
}

\author{
${ }^{1}$ Idil Afrialdi , Eri Dahlan, ${ }^{3}$ Susiana \\ ${ }^{1}$ Mahasiswa Teknik Sipil Universitas Batanghari Jambi \\ ${ }^{2,3}$ Dosen Fakultas Teknik Univesitas Batanghari Jambi
}

\begin{abstract}
ABSTRAK
Pembangunan dan Pengembangan Perekonomian Daerah Provinsi Jambi di Kabupaten Tanjung Jabung Timur sangat tergantung pada sarana dan prasarana yang ada pada wilayah tersebut. Terhambatnya pembangunan dan perekonomian suatu wilayah bisa diakibatkan kurangnya prasarana transportasi. Untuk memenuhi pengguna jalan maka perkerasan harus memenuhi persyaratan kondisi fungsional dan struktural. Dimana persyaratan fungsional adalah menyangkut kerataan dan kekesatan permukaan perkerasan, sedangkan persyaratan struktural adalah kekuatan atau daya dukung perkerasan yang dinyatakan dalam nilai struktural atau lendutan. Jalan Teluk Dawan - Teluk Buan yang terdapat di Kec. Dendang ini menghubungkan antara Jalan kecamatan ke Ibukota Muara Sabak yang bertujuan untuk memberi kenyamanan dan kelancaran bagi pengguna jalan, serta diharapkan dapat membantu meningkatkan perekonomian masyarakat sekitar, seperti: Pinang, dan Kelapa sawit. Dari Metode Analisa Komponen (SNI 17321989-F) didapatkan tebal lapis perkerasan diperoleh dari nilai LHR awal umur rencana sebesar 2084 dan LHR akhir umur rencana sebesar 3395 dengan umur rencana 10 tahun, dan nilai CBR 3,4\% maka dapat tebal lapis permukaan untuk Asphalt Concrete Binder Course (AC-BC) dengan tebal $15 \mathrm{~cm}$, sedangkan untuk lapis pondasi atas $20 \mathrm{~cm}$, dan lapis pondasi bawah $10 \mathrm{~cm}$.
\end{abstract}

Kata kunci: Lapis Perkerasan Jalan AC-BC Teluk Dawan - Teluk Buan

\section{PENDAHULUAN}

Pembangunan dan Pengembangan Perekonomian Daerah Provinsi Jambi di Kabupaten Tanjung Jabung Timur sangat tergantung pada sarana dan prasarana yang ada pada wilayah tersebut. Terhambatnya pembangunan dan perekonomian suatu wilayah bisa diakibatkan kurangnya prasarana transportasi. Jalan Teluk Dawan - Teluk Buan yang terdapat di Kec. Dendang ini menghubungkan antara Jalan kecamatan ke Ibukota Muara Sabak yang bertujuan untuk memberi kenyamanan dan kelancaran bagi pengguna jalan, serta diharapkan dapat membantu meningkatkan perekonomian masyarakat sekitar, seperti: Pinang, dan Kelapa sawit. Pada saat ini, konstruksi perkerasan jalan di Indonesia semakin berkembang, mulai dari Perkerasan Jalan menggunakan Perkerasan Lentur (Flexible Pavement) dan Perkerasan Kaku (Rigid Pavement). Secara umum, terdapat tiga (3) tipe Perkerasan Jalan yang digunakan, yaitu Perkerasan Lentur (Flexible Pavement), Perkerasan Kaku (Rigid Pavement), dan Perkerasan Komposit (Composite Pavement) yang masing-masing mempunyai kelebihan dan kekurangan. Salah satu jenis perkerasan lentur yang digunakan adalah Lapis Aspal Beton (Laston) campuran lapisan tersebut terdiri dari agregat kasar, agregat halus, bahan pengisi (Filler) dan aspal. Lapisan campuran aspal memiki keunggulan karakteristik yaitu: Stabilitas (Stability), Keawetan (Durabilitas), Kelenturan (Fleksibilitas), Kekesatan / tahanan geser (Skid Resistance), kedap air (Impermeabilitas), Mudah dilaksanakan (Workability), dan ketahanan terhadap kelelehan (Fatique Resistance). Secara umum lapis perkerasan lentur terdiri dari lapis aus permukaan Asphalt Concrete Wearing Course (AC-WC), lapis pengikat atau lapis antara Asphalt Concrete Binder Course (AC-BC), dan lapis pondasi Asphalt Concrete Base (AC-Base). Dalam proses pencampuran, jumlah tumbukan dan suhu dalam pemadatan campuran aspal sangat berpengaruh terhadap karakteristik lapisan campuran aspal itu sendiri. Campuran beraspal panas untuk perkerasan lentur di rancang menggunakan metode Marshall.

Lapisan aspal beton adalah jenis Perkerasan Jalan yang terdiri dari campuran agregat dan aspal, atau tanpa bahan tambahan. Material-material pembentuk beton aspal dicampur di instalasi pencampur pada suhu tertentu, kemudian diangkut ke lokasi, dihamparkan dan dipadatkan. Suhu pencampuran ditentukan berdasarkan jenis aspal yang akan digunakan. Jika semen aspal, maka pencampuran umumnya antara 145$155^{\circ} \mathrm{C}$, sehingga disebut beton aspal campuran panas. Campuran ini dikenal dengan nama (hotmix). Beton 
aspal yang menggunakan aspal cair dapat dicampur pada suhu ruang, sehingga dinamakan (coldmix) (Silvia Sukirman, 2003). (Menurut Spesifikasi Umum Revisi 3 Divisi VI Bina Marga 2010). Sebagai lapis permukaan perkerasan jalan, Laston (AC) mempunyai nilai struktur, kedap air, dan mempunyai stabilitas tinggi.

Sesuai fungsinya Laston (AC) mempunyai 3 macam campuran yaitu:

1. Laston sebagai lapisan aus, dikenal dengan nama AC-WC (Asphalt Concrete-Wearing Course), dengan tebal nominal minimum adalah $4 \mathrm{~cm}$.

2. Laston sebagai lapisan antara, dikenal dengan nama AC-BC (Asphalt Concrete-Binder Course), dengan tebal nominal minimum adalah $6 \mathrm{~cm}$.

3. Laston sebagai lapisan pondasi, dikenal dengan nama AC-Base (Asphalt Concrete-Base), dengan tebal nominal minimum adalah $7,5 \mathrm{~cm}$.

Jenis beton aspal campuran panas yang ada di Indonesia saat ini adalah:

1. Laston (Lapisan Aspal Beton), adalah beton aspal bergradasi menerus yang umum diguanakan untuk jalan-jalan dengan beban lalu lintas berat. Laston dikenal pula dengan nama AC (Asphalt Concrete). Karateristik beton aspal yang terpenting pada campuran ini adalah stabilitas. Tebal nominal minimum Laston 4-7,5 cm (Spesifikasi Umum Revisi 3 Divisi VI Bina Marga 2010).

2. Lataston (Lapisan Tipis Aspal Beton), adalah beton aspal bergradasi senjang. Lataston biasa pula disebut dengan HRS (Hot Rolled Sheet).

3. Latasir (Lapisan Tipis Aspal Pasir), adalah beton aspal untuk jalan-jalan dengan lalu lintas ringan, khususnya dimana agregat kasar tidak atau sulit diperoleh.

Agregat atau batu atau granular material adalah material berbutir yang keras dan kompak. Istilah agregat mencakup antara lain batu bulat, batu pecah, abu batu, dan pasir. Agregat mempunyai peranan yang sangat penting dalam prasarana transportasi, khususnya dalam hal ini pada perkerasan jalan. Pemeriksaan keausan agregat dengan mesin Abrasi Los Angeles sesuai dengan SNI 2417 - 2008. Agregat sebagai suatu bahan yang terdiri dari mineral padat, berupa masa berukuran besar ataupun berupa fragmen-fragmen. Agregat merupakan komponen utama dari struktur perkerasan jalan, yaitu 90-95\% agregat. berdasarkan persentase berat atau 75-85\% agregat berdasarkan persentase volume. Dengan demikian kualitas perkerasan jalan ditentukan juga dari sifat agregat dan hasil campuran agregat dengan material lain. (Silvia Sukirman, 2003).

Berdasarkan ukuran butiran agregat dapat dibedakan atas agregat kasar, agregat halus, dan bahan pengisi (filler). Batasan dari masing-masing agregat ini sering kali berbeda, sesuai institusi yang menentukannya. The Asphalt Institut dan Depkimpraswil dalam Spesifikasi Baru Campuran Panas,2002 membedakan agregat menjadi:

a. Agregat Kasar, adalah agregat dengan ukuran butir lebih besar dari saringan No.8 $(=2,36 \mathrm{~mm})$.

b. Agregat Halus, adalah agregat dengan ukuran butir lebih halus dari saringan No.8 (=2,36 mm).

c. Bahan Pengisi (filler), adalah bagian dari agregat halus yang lolos saringan No.30 $(=0,60 \mathrm{~mm})$ (Sukirman, 2003).

Pembagian Agregat Berdasarkan Ukuran Butiran Menurut Spesifikasi Umum Revisi 3 Divisi VI Bina Marga (2010):

a. Agregat Kasar, adalah agregat dengan ukuran butiran lebih besar yang tertahan saringan No. 4 (4,75 $\mathrm{mm})$.

b. Agregat Halus, adalah agregat dengan ukuran butiran lebih halus yang Lolos Saringan No.4 (4,75 mm).

c. Bahan Pengisi (filler), adalah bagian dari agregat halus yang minimum 75\% Lolos Saringan No. 200 $(0,075 \mathrm{~mm})$.

Berdasarkan tempat yang diperoleh, Aspal dibedakan atas 2 (dua) jenis sebagai berikut:

1. Aspal Alam

Merupakan aspal yang berasal dari proses alam, dan dapat digunakan sebagaimana diperolehnya atau dengan sedikit pengolahan. Aspal alam ada yang diperoleh dari gunung-gunung seperti di Pulau Buton, dan ada pula di danau-danau seperti di Trinidad.Trinidad merupakan aspal alam terbesar di dunia, berupa aspal danau atau disebut Trinidad Lake Asphalt. 
2. Aspal Minyak / Buatan

Aspal minyak adalah aspal yang merupakan sebagai bahan baku atau residu pengilangan minyak bumi yang mempunyai kadar paraffin yang rendah dan disebut dengan Paraffin Base Crude Oil.

Berdasarkan bentuk Aspal Buatan dibedakan dalam 3 jenis antara lain:

1. Aspal Keras (Asphalt Cement)

Aspal keras pada suhu ruang $(250-300 \mathrm{C})$ berbentuk padat. $A C$ dibedakan berdasarkan nilai penetrasi (tingkat kekerasannya). Untuk Aspal dengan penetrasi rendah digunakan di daerah bercuaca panas, volume lalu lintas tinggi sedangkan aspal dengan penetrasi tinggi digunakan untuk daerah bercuaca dingin, lalu lintas rendah. Aspal keras yang biasa digunakan yaitu:

1) Aspal penetrasi 40/50, yaitu AC dengan penetrasi antara 40-50.

2) Aspal penetrasi 60/70, yaitu AC dengan penetrasi antara 60-70.

3) Aspal penetrasi 80/100, yaitu AC dengan penetrasi antara 80/100.

4) Aspal penetrasi 120/150, yaitu AC dengan penetrasi antara 120/150.

5) Aspal penetrasi 200/300, yaitu AC dengan penetrasi antara 200/300.

2. Aspal Cair (Cut Back Asphalt)

Aspal cair adalah aspal keras yang di campur dengan pelarut. campuran antara aspal keras dengan bahan pencair dari hasil penyulingan minyak bumi. Maka berbentuk cair dalam temperatur ruang. aspal cair digunakan untuk keperluan lapis resap pengikat (Prime Coat).

3. Aspal Emulsi

Aspal emulsi adalah suatu campuran aspal dengan air dan bahan pengemulsi. Aspal emulsi terdiri dari butir-butir aspal halus dalam air yang diberikan muatan listrik sehingga butir-butir aspal tersebut tidak bersatu dan tetap berada pada jarak yang sama.

Berdasarkan kecepatan pengerasannya aspal emulsi dapat dibedakan atas :

1) RS (Rapid Setting), aspal yang mengandung sedikit bahan pengemulsi sehingga pengikatan cepat terjadi. Digunakan untuk Lapis Perekat (Take Coat).

2) MS (Medium Setting). Digunakan untuk Seal Coat.

3) SS (Slow Setting), jenis aspal emulsi yang paling lambat menguap. Digunakan untuk Lapis Pengikat (Prime Coat).

Aspal yang digunakan sebagai material perkerasan jalan berfungsi sebagai berikut:

a) Sebagai bahan pengikat yang memberikan ikatan yang kuat antara aspal dengan agregat dan antara sesama aspal.

b) Sebagai bahan pengisi yang berfungsi mengisi rongga antara butir-butir agregat dan rongga yang ada dalam agregat itu sendiri.

\section{METODE PENELITIAN}

Perhitungan secara teoritis dilakukan berdasarkan data-data yang diperoleh dari buku panduan atau data teknis dari spesifikasi aspal yang digunakan di lapangan, serta data yang diperoleh dari referensireferensi perhitungan. Perhitungan dihitung berdasarkan data primer dan data sekunder.

\section{HASIL DAN PEMBAHASAN}

Tabel 1 Nilai LHR survei

\begin{tabular}{clc}
\hline No & \multicolumn{1}{c}{ Jenis Kendaraan } & LHRs (Kendaraan/hari/2 arah) \\
\hline 1 & Kendaraan Ringan & 865 \\
2 & Bus kecil & 99 \\
3 & Bus besar & 3 \\
4 & Truck 2 as & 850 \\
5 & Truck 3 as & 57 \\
6 & Truck 4 as Gandeng & 1 \\
7 & Truck Semi Trailer & 34 \\
& $\quad$ Jumlah Total & 1909 \\
\hline
\end{tabular}

Sumber : Dinas PU Kab. Tanjab Timur, 2013 
Perhitungan Lalu Lintas Harian Rata-rata ( LHR)

1. LHR Awal Umur Rencana (LHR 2016)

$=$ LHR $2013(1+0,03)^{3}$

$=865 \times(1+0,03)^{3}=945$

2. LHR Akhir Umur Rencana (LHR 2026)

$=$ LHR $2016(1+0,05)^{10}$

$=945 \times(1+0,05)^{10}=1539$

Tabel 2. Perhitungan Lalu Lintas Harian Rata-rata

\begin{tabular}{llccc}
\hline No. & Jenis Kendaraan & LHR Awal Perencanaan & $\begin{array}{c}\text { LHR Awal Umur Rencana } \\
\text { (LHR 2016) } \\
\text { LHR 2013 (1+0,03) }\end{array}$ & $\begin{array}{c}\text { LHR Akhir Umur Rencana } \\
(\text { LHR 2026) }\end{array}$ \\
\hline 1 & & LHR 2013 & 945 & 1539 \\
LendaraanRingan & 865 & 108 & 176 \\
2 & Bus Kecil & 99 & 3 & 5 \\
3 & Bus Besar & 3 & 928 & 1512 \\
4 & Truck 2 as & 850 & 62 & 101 \\
5 & Truck 3 as & 57 & 1 & 2 \\
6 & Truck 4 as Gandeng & 1 & 37 & 60 \\
7 & Truck Semi Trailer & 34 & 2084 & 3395 \\
\hline
\end{tabular}

\section{Perhitungan Angka Ekivalen (E) Masing-masing Kendaraan}

Beban sumbu kendaraan angka perbandingan tingkat kerusakan akibat beban sumbu tunggal terhadap standar adalah 8,16 Ton. Jadi Beban Sumbu Kendaraan dapat dihitung sebagai berikut :

a. Angka Ekivalen Sumbu Tunggal

$E=\left[\frac{\text { Beban satu sumbutunggal }(\mathrm{kg})}{8160}\right]^{4}$

b. Angka Ekivalen Sumbu Ganda

$E=0,086\left[\frac{\text { Beban satu sumbu ganda }(\mathrm{kg})}{8160}\right]^{4}$

Tabel 2 Nilai Ekivalen (E) Sumbu Kendaraan

\begin{tabular}{|c|c|c|c|c|c|c|c|c|}
\hline \multirow{3}{*}{ Jenis Kendaraan } & \multirow{3}{*}{$\begin{array}{l}\text { Berat Total } \\
\text { ( Ton) }\end{array}$} & \multicolumn{4}{|c|}{ Distribusi Beban } & \multicolumn{2}{|c|}{ Sumbu Ekivalen (E) } & \multirow{3}{*}{ E Total } \\
\hline & & \multicolumn{2}{|c|}{ \% Berat } & \multicolumn{2}{|c|}{ Berat } & \multirow{2}{*}{$\begin{array}{c}\text { Depan } \\
\text { Tunggal } \\
\end{array}$} & \multirow{2}{*}{\begin{tabular}{|c|} 
Belakang \\
Ganda \\
\end{tabular}} & \\
\hline & & Depan & Belakang & Depan & Belakang & & & \\
\hline Kendaraan Ringan & 2 & 50 & 50 & 1 & 1 & 0.0002 & 0.0002 & 0.0004 \\
\hline Bus Kecil & 6 & 34 & 66 & 2.040 & 3.960 & 0.0039 & 0.0048 & 0.0087 \\
\hline Bus Besar & 9 & 34 & 66 & 3.060 & 5.940 & 0.0198 & 0.0241 & 0.0439 \\
\hline Truck 2 As & 18 & 34 & 66 & 6.120 & 11.880 & 0.3164 & 0.3864 & 0.7028 \\
\hline Truck 3 As & 25 & 25 & 75 & 6.250 & 18.750 & 0.3442 & 2.3974 & 2.7416 \\
\hline Truck 4 As Gandeng & 30 & 18 & 54 & 5.400 & 16.200 & 0.1918 & 1.3360 & 1.5278 \\
\hline Truck Semi Trailer & 27 & 18 & 54 & 4.860 & 14.580 & 0.1258 & 0.8765 & 1.0023 \\
\hline
\end{tabular}

Sumber : Data Olahan Tugas Akhir, 2018

1. Menghitung LEP (Lintas Ekivalen Permulaan)

Rumus $=\Sigma$ LHR Awal $\times$ C x E Total

\begin{tabular}{rllll} 
Kendaraan Ringan & $=945 \times 0,50 \times 0,0004$ & $=0,1890$ \\
Bus Kecil & $=108 \times 0,50 \times 0,0087$ & $=0,4698$ \\
Bus Besar & $=3$ & $\times 0,50 \times 0,0439$ & $=0,0659$ \\
Truck 2 as & $=928 \times 0,50 \times 0,7028$ & $=326,0992$ \\
Truck 3 as & $=62$ & $\times 0,50 \times 2,7416$ & $=84,9896$ \\
Truck 4 as Gandeng $=1$ & $\times 0,50 \times 1,5278$ & $=0,7639$ \\
Truck Semi Trailer $=37$ & $\times 0,50 \times 1,0023$ & $=18,5426+$ \\
\hline & Total & $=431,12$
\end{tabular}


2. Menghitung LEA (Lintas Ekivalen Akhir)

Rumus $=\Sigma$ LHR Akhir $\times$ C x E Total

Kendaraan Ringan $=1539 \times 0,50 \times 0,0004=0,3078$

Bus Kecil $\quad=176 \times 0,50 \times 0,0087=0,7656$

Bus Besar $\quad=5 \times 0,50 \times 0,0439=0,1098$

Truck 2 as $\quad=1512 \times 0,50 \times 0,7028=531,3168$

Truck 3 as $\quad=101 \times 0,50 \times 2,7416=138,4508$

Truck 4 as Gandeng $=2 \times 0,50 \times 1,5278=1,5278$

$\begin{array}{ccc}\text { Truck Semi Trailer }=60 \times 0,50 \times 1,0023 & =30,0690+ \\ \text { Total } & =702,54\end{array}$

3. Menghitung LET (Lintas Ekivalen Tengah)

Rumus $\quad=\underline{\text { LEP }+ \text { LEA }}$

LET $\quad=\frac{431,12+702,54}{2}=566,830$

4. Menghitung LER (Lintas Ekivalen Rencana)

Rumus $\quad=$ LER $=$ LET $\times$ UR/10

$$
=566,830 \times 10 / 10=566,830
$$

5. Mencari ITP (Indeks Tebal Perkerasan)

CBR Segmen Tanah Dasar $=3,4 \%$

DDT $=4,3 \log \mathrm{CBR}+1,7$

$$
=4,3 \log (3,4)+1,7=4
$$

6. Indeks Permukaan Awal Umur Rencana (IPo)

Lapis Permukaan "Laston"

LER $=566,830 \leq 1000$, Maka $($ IPo $)=\geq 4$

7. Indeks Permukaan Akhir Umur Rencana (IPt)

Fungsi Jalan " Kolektor"

$\mathrm{LER}=566,830 \leftrightarrow(100-1000)$, Maka $(\mathrm{IPt})=2,0$

8. Grafik Nomogram 4

ITP $=10$

ITP $=10$

$\underline{\mathrm{TP}}=(\mathrm{a} 1 \times \mathrm{D} 1)+(\mathrm{a} 2 \times \mathrm{D} 2)+(\mathrm{a} 3 \times \mathrm{D} 3)$

$10=(0,40 \times \mathrm{D} 1)+(0,14 \times 20)+(0,13 \times 10)$

$10=(0,40 \times \mathrm{D} 1)+2,80+1,30$

$\mathrm{D} 1=\frac{10-4,10}{0,40}=14,75 \mathrm{Cm}=15 \mathrm{~cm}$ (dibulatkan)

Grafik Nomogram 4

ITP $=10$

ITP $=10$

$\underline{\mathrm{ITP}}=(\mathrm{a} 1 \times \mathrm{D} 1)+(\mathrm{a} 2 \times \mathrm{D} 2)+(\mathrm{a} 3 \times \mathrm{D} 3)$

$10=(0,40 \times 15)+(0,14 \times \mathrm{D} 2)+(0,13 \times 10)$

$10=6,00+(0,14 \times \mathrm{D} 2)+1,30$

$\mathrm{D} 2=\frac{10-7,30}{0,14}=19,29 \mathrm{Cm}=20 \mathrm{~cm}$ (dibulatkan) 


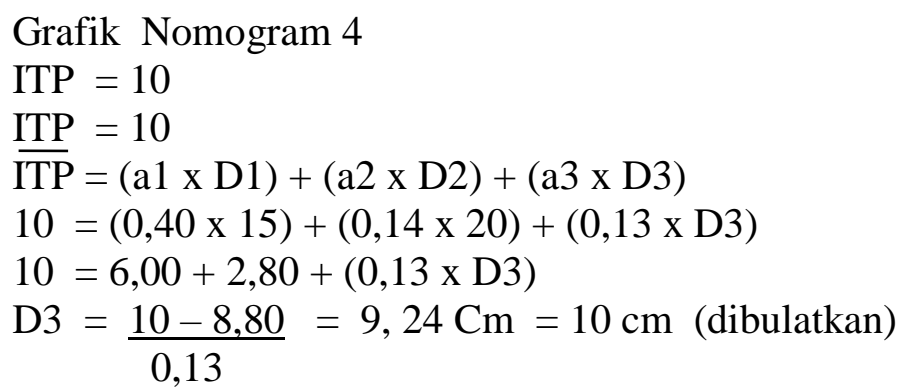

9. Koefisien Kekuatan Relatif :

a1 $=0,40$ (Laston)

a2 $=0,14$ (Batu Pecah Kelas A)

a3 = 0,13 (Batu Pecah Kelas B)

10. Tebal Lapis Perkerasan :

$\mathrm{D} 1=15 \mathrm{~cm}$ (Laston)

$\mathrm{D} 2=20 \mathrm{~cm}($ Kelas A)

D3 $=10 \mathrm{~cm}($ Kelas B)

\section{SIMPULAN}

Berdasarkan dari hasil analisis dalam penelitian ini didapatkan Tebal Perkerasan Jalan Asphalt Concrete - Binder Couse (AC-BC) dengan kondisi tanah dasar yang nilai CBR 3,4 \% adalah $15 \mathrm{~cm}$, maka untuk penyelesaian selanjutnya terjadi perbaikan tanah dasar. Jadi diasumsikan setelah diperbaiki tanah dasar tersebut maka nilai CBR bisa naik jadi 8\%, dengan tebal di dapat $10 \mathrm{~cm}$.maka jalan tersebut bisa direncanakan dengan menggunakan aspal.

Dari hasil perhitungan Perkerasan Lentur dengan CBR 3,4\%, maka didapat:

1. Lapisan antara $(\mathrm{AC}-\mathrm{BC})=15 \mathrm{~cm}$

2. Lapisan Pondasi Atas $=20 \mathrm{~cm}$

3. Lapisan Pondasi Bawah $=10 \mathrm{~cm}$

Dari hasil perhitungan Perkerasan Lentur dengan CBR 8\%, maka didapat:

1. Lapisan antara $(\mathrm{AC}-\mathrm{BC})=10 \mathrm{~cm}$

2. Lapisan Pondasi Atas $=20 \mathrm{~cm}$

3. Lapisan Pondasi Bawah $=10 \mathrm{~cm}$

\section{DAFTAR PUSTAKA}

Budi Raharjo, 2016. Pengaruh suhu pemadatan untuk perkerasan Lapis antara (AC-BC) Bandar Lampung, Universitas Lampung.

CBR Segmen dengan Dynamic Cone Penetrometer (DCP) Tahun 2017, Universitas Batanghari Jambi.

Departemen Pekerjaan Umum SNI 1732 -1989-F. Petunjuk Perencanaan Tebal Perkerasan Lentur Dengan

Metode Analisa Komponen.

Departemen Pekerjaan Umum Direktorat Jenderal Bina Marga Manual Perkerasan Jalan dengan Alat Benkelman Beam No. 01/MN/BM/83.

Perencanaan Jalan Teluk Dawan- Teluk Buan Tahun 2013, Dinas Pekerjaan Umum dan Penataan Ruang Kabupaten Tanjung Jabung Timur.

Perancangan Perkerasan Jalan Tahun 2014, Tugas Besar Mata Kuliah Universitas Batanghari Jambi.

Sukirman Silvia, 2010. Perencanaan Tebal Struktur Perkerasan Lentur, Nova Bandung.

Spesifikasi Umum Revisi 32010 Divisi 6 Perkerasan Beraspal. Kementerian Pekerjaan Umum. Jakarta.

Sukirman. Silvia, 2003. Beton Aspal Campuran Panas, Granit, Jakarta.

Undang-undang Republik Indonesia No. 38 Tahun 2004 Tentang Jalan. 